\title{
Liquid - Liquid Equilibria of Methanol + Toluene + Hexane Ternary System at 278.15, 283.15, 288.15 and $293.15 \mathrm{~K}$
}

\author{
Jonatan H Veliz, Alicia Cases, Diego A González, Constanza Geraldine Varas Gutierrez, Geraldine Galvez and \\ Mónica B Gramajo* \\ Instituto de Física del Noroeste Argentino, National University of Tucumán, Argentina
}

Submission: April 25, 2017, Published: September 19, 2017

*Corresponding author: Mónica B Gramajo, Instituto de Física del Noroeste Argentino (INFINOA-CONICET) Facultad de Ciencias Exactas y

Tecnología, National University of Tucumán, Tucumán, Argentina, Email: mgramajo@herrera.unt.edu.ar

\begin{abstract}
Liquid-liquid equilibria of methanol + ethylbenzene + methylcyclohexane ternary system at 278.15, 283.15, and 293.15K are reported. The effect of the temperature on liquid-liquid equilibrium is discussed. All chemicals were quantified by gas chromatography using a thermal conductivity detector. Experimental data for the ternary system are compared with values calculated by the NRTL and UNIQUAC equations. It is found that the UNIQUAC equation fitted to the experimental data is more accurate than the NRTL model for this ternary system.
\end{abstract}

Keywords: Liquid- liquid; Methanol; Toluene; Hexane; Equilibria

\section{Introduction}

There are increasing demands for use oxygenated compounds to produce reformulated gasoline. For this reason, we are studying the phase equilibrium of systems containing hydrocarbons and oxygenated compounds. Within the oxygenated compounds, ethers and alcohols are the most important, and among these, methanol is receiving much current attention [1-6]. Methanol presents partial miscibility with aliphatic hydrocarbons, but not with aromatic hydrocarbons. Therefore, it is of great importance to study systems composed by methanol and representative hydrocarbon of gasoline, establishing the concentration ranges and the temperature of hydrocarbons and methanol in which the two-phase region does not exist [7].

In order to obtain the behaviour of blends of hydrocarbons and methanol at four temperatures, liquid- liquid equilibrium data have been obtained for methanol + toluene + hexane ternary system at 278.15, 283.15, 288 [8]. 15 and $293.15 \mathrm{~K}$ with constancy in temperature of $\pm 0.05 \mathrm{~K}$. The equilibrium concentration for each component was determined by gas chromatography, using the internal standard method. The plait point coordinates at each temperature are reported. The experimental results were compared with those correlated with the NRTL [9] and UNIQUAC [10] models fitted to those experimental results.

\section{Experimental Sections}

\section{Materials}

Methanol, toluene and hexane were supplied by Merck. The purity of the chemicals was verified chromatographically using a HP 6890 gas chromatograph with a TCD detector coupled to a Chem Station and nitrogen as gas carrier, showing that their mass fractions were higher than 0.99. Therefore, they were used without further purification.

\section{Apparatus and Procedures}

The experimental procedure used is the same as that reported in a previous work [11]. All components in the conjugated phases were quantified by chromatography applying the internal standard method. Acetone (Merck, chromatographic quality) with a mass fraction purity $>0.999$ (GC) was the standard compound used for this purpose. A Hewlett Packard 6890 gas chromatograph with an automatic injector (Agilent G2613A) directly connected to a Chem Station (HP G2070AA) was used. Good separation of the three components was obtained on a $30 \mathrm{~m}$ long $\mu .25 \mathrm{~mm}$ id $\mu 0.5 \mu \mathrm{m}$ film thickness capillary column (INNO Wax, crosslinked polyethylene glycol, HP 19091N-233). The temperature program used was: initial temperature $343 \mathrm{~K}$ for two minutes, ramp $50 \mathrm{Kmin}^{-1}$, and final temperature $473 \mathrm{~K}$ for another one 
minute. The nitrogen carrier gas flow rate was electronically kept constant working with a split ratio of 20:1 and with the injector maintained at $453 \mathrm{~K}$. Detection was carried out by a thermal conductivity detector at 523K. Three analyses were performed for each sample in order to obtain a mean mass fraction value with repeatability better than one percent.

\section{Results and Discussion}

Table 1: Experimental data of $\left(w_{1}\right.$ methanol $+w_{2}$ toluene $+w_{3}$ hexane) ternary system at four temperatures; wi denotes mass fraction.

\begin{tabular}{|c|c|c|c|c|c|c|c|c|c|}
\hline \multirow[t]{2}{*}{$\mathbf{T} / \mathbf{K}$} & \multicolumn{3}{|c|}{ Overall Compositions } & \multicolumn{3}{|c|}{ Methanol - Rich Phase } & \multicolumn{3}{|c|}{ Hexane - Rich Phase } \\
\hline & $\mathrm{w}_{1}$ & $\mathrm{w}_{2}$ & $\mathrm{w}_{3}$ & $\mathrm{w}_{1}$ & $\mathrm{w}_{2}$ & $\mathrm{w}_{3}$ & $\mathrm{w}_{1}$ & $\mathrm{w}_{2}$ & $\mathrm{w}_{3}$ \\
\hline \multirow[t]{6}{*}{278.15} & 0.4603 & 0 & 0.5397 & 0.775 & 0 & 0.225 & 0.049 & 0 & 0.951 \\
\hline & 0.4294 & 0.0421 & 0.5285 & 0.717 & 0.036 & 0.247 & 0.058 & 0.05 & 0.892 \\
\hline & 0.4213 & 0.058 & 0.5207 & 0.703 & 0.046 & 0.251 & 0.069 & 0.073 & 0.858 \\
\hline & 0.4119 & 0.0809 & 0.5072 & 0.669 & 0.065 & 0.266 & 0.083 & 0.101 & 0.816 \\
\hline & 0.3895 & 0.1233 & 0.4872 & 0.577 & 0.116 & 0.307 & 0.113 & 0.134 & 0.753 \\
\hline & 0.355 & 0.153 & 0.492 & 0.52 & 0.145 & 0.335 & 0.148 & 0.163 & 0.689 \\
\hline $\mathrm{PP}^{\mathrm{a}}$ & & & & 0.296 & 0.202 & 0.502 & 0.296 & 0.202 & 0.502 \\
\hline $\mathrm{PP}^{\mathrm{b}}$ & & & & 0.303 & 0.201 & 0.496 & 0.303 & 0.201 & 0.496 \\
\hline \multirow[t]{6}{*}{283.15} & 0.3354 & 0 & 0.6646 & 0.731 & 0 & 0.269 & 0.062 & 0 & 0.938 \\
\hline & 0.3042 & 0.0362 & 0.6595 & 0.696 & 0.023 & 0.281 & 0.076 & 0.044 & 0.88 \\
\hline & 0.2886 & 0.0645 & 0.6469 & 0.674 & 0.037 & 0.29 & 0.098 & 0.079 & 0.823 \\
\hline & 0.2657 & 0.0947 & 0.6396 & 0.588 & 0.067 & 0.346 & 0.113 & 0.109 & 0.779 \\
\hline & 0.2536 & 0.1232 & 0.6232 & 0.533 & 0.108 & 0.359 & 0.119 & 0.131 & 0.75 \\
\hline & 0.2414 & 0.154 & 0.6046 & 0.44 & 0.143 & 0.418 & 0.167 & 0.158 & 0.675 \\
\hline $\mathrm{PP}^{\mathrm{a}}$ & & & & 0.267 & 0.184 & 0.549 & 0.267 & 0.184 & 0.549 \\
\hline $\mathrm{PP}^{\mathrm{b}}$ & & & & 0.271 & 0.168 & 0.561 & 0.271 & 0.168 & 0.561 \\
\hline \multirow[t]{5}{*}{288.15} & 0.3111 & 0 & 0.6889 & 0.702 & 0 & 0.298 & 0.074 & 0 & 0.926 \\
\hline & 0.3184 & 0.0347 & 0.6469 & 0.66 & 0.023 & 0.317 & 0.093 & 0.043 & 0.864 \\
\hline & 0.2939 & 0.066 & 0.6401 & 0.625 & 0.045 & 0.33 & 0.119 & 0.076 & 0.805 \\
\hline & 0.2937 & 0.0918 & 0.6145 & 0.582 & 0.071 & 0.347 & 0.145 & 0.103 & 0.752 \\
\hline & 0.2725 & 0.1236 & 0.6039 & 0.503 & 0.106 & 0.391 & 0.189 & 0.13 & 0.681 \\
\hline $\mathrm{PP}^{\mathrm{a}}$ & & & & 0.327 & 0.151 & 0.522 & 0.327 & 0.151 & 0.522 \\
\hline $\mathrm{PP}^{\mathrm{b}}$ & & & & 0.328 & 0.151 & 0.521 & 0.328 & 0.151 & 0.521 \\
\hline \multirow[t]{5}{*}{293.15} & 0.3237 & 0 & 0.6763 & 0.66 & 0 & 0.34 & 0.084 & 0 & 0.916 \\
\hline & 0.3031 & 0.0244 & 0.6725 & 0.628 & 0.017 & 0.355 & 0.098 & 0.029 & 0.873 \\
\hline & 0.2995 & 0.0451 & 0.6554 & 0.587 & 0.036 & 0.377 & 0.116 & 0.051 & 0.833 \\
\hline & 0.2778 & 0.054 & 0.6682 & 0.57 & 0.042 & 0.388 & 0.13 & 0.06 & 0.81 \\
\hline & 0.2976 & 0.0782 & 0.6242 & 0.493 & 0.071 & 0.436 & 0.169 & 0.083 & 0.748 \\
\hline $\mathrm{PP}^{\mathrm{a}}$ & & & & 0.31 & 0.105 & 0.585 & 0.31 & 0.105 & 0.585 \\
\hline $\mathrm{PP}^{\mathrm{b}}$ & & & & 0.307 & 0.106 & 0.587 & 0.307 & 0.106 & 0.587 \\
\hline
\end{tabular}

"Zero" means that the component is absent.

aEstimated plait point by the UNIQUAC model.

bEstimated plait point by the NRTL model.

(Table 1) report the liquid - liquid equilibrium (LLE), expressed in mass fraction, of $\left(w_{1}\right.$ methanol $+w_{2}$ toluene $+w_{3}$ hexane) ternary system at $(278.15,283.15,288.15$ and $293.15 \pm$ $0.05)$ K. Figure 1 shows experimental ternary equilibrium data at the four temperatures studied here. As can be seen, a good
We prepare several ternary mixtures with very well known concentrations by mass in order to obtain the uncertainty in the equilibrium mass fraction values. These mixtures were analysed with the chromatographic method, and their chromatographic concentrations were compared with those obtained by mass. This comparison shows that the reported mass fraction values have an uncertainty o $\phi \pm 0.004$. 
Figure 1 shows that this ternary system can be classified as type1 in the Treybal's classification [12].

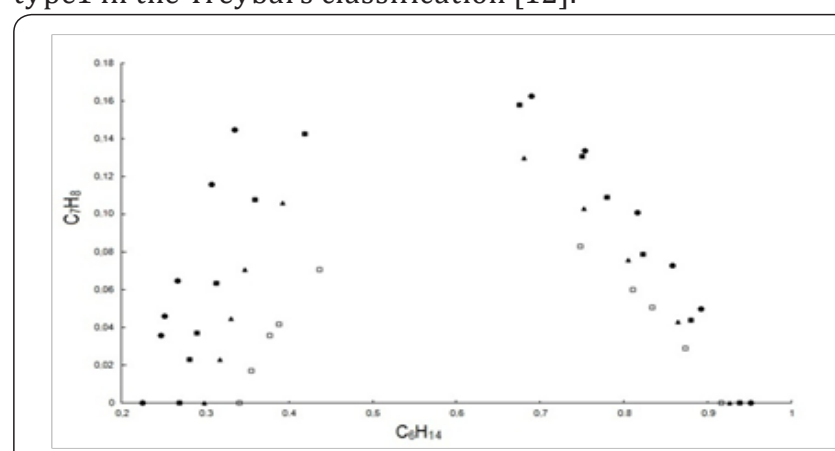

Figure 1: (Liquid + liquid) equilibrium of $\left\{\mathrm{w}_{1} \mathrm{CH}_{4} \mathrm{O}+\mathrm{w}_{2} \mathrm{C}_{7} \mathrm{H}_{8}\right.$ $\left.+\mathrm{w}_{3} \mathrm{C}_{6} \mathrm{H}_{14}\right\}$ ternary system at $\mathrm{T}=\{278.15(\bullet), 283.15(\bullet)$, 288.15( $\mathbf{\Delta}), 293.15(\square)\} \mathrm{K}$.

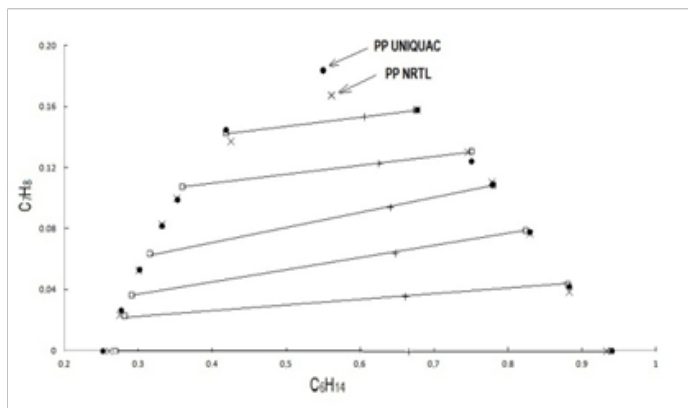

Figure 2: (Liquid + liquid) equilibrium of $\left\{\mathrm{w}_{1} \mathrm{CH}_{4} \mathrm{O}+\mathrm{w}_{2} \mathrm{C}_{7} \mathrm{H}_{8}+\right.$ $\left.\mathrm{w}_{3} \mathrm{C} \mathrm{H}_{14}\right\}$ ternary system at $\mathrm{T}=283.15 \mathrm{~K}$. - . Experimental; $\mathrm{X}$, NRTL; $\bullet$ UNIQUAC; +, global compositions.

Since the concentrations of the three components were individually determined, the sums of the mass fractions for each phase in Table 1 may slightly differ from unity. Material balances [13] were performed for each tine line at each temperature in order to check the consistency of the equilibrium experimental data reported in Table 1. These calculations show that our data satisfy the mass balance within an average absolute deviation of $1.8,2.0,1.8$ and 0.3 percent at $(278.15,283.15,288.15$ and 293.15) $\mathrm{K}$ with a greatest deviation of $2.3,2.8,2.4$ and 0.5 percent, respectively.

The LLE data for the ternary system studied here were correlated by the UNIQUAC and NRTL activity coefficient models, using an iterative computer program developed by Sørensen [14] that minimizes the values of the following objective functions:

$$
\begin{gathered}
\mathrm{F}_{a}=\sum^{k} \sum^{i}\left\{\left(\mathrm{a}_{i k}^{I}-\mathrm{a}_{i k}^{I I}\right) /\left(\mathrm{a}_{i k}^{I}+\mathrm{a}_{i k}^{I I}\right)\right\}^{2}+\mathrm{Q} \sum^{\mathrm{n}} \mathrm{P}_{n}^{2} \\
\mathrm{~F}_{x}=\sum^{k} \min \sum^{i} \sum^{j}\left(\mathrm{x}_{i j k}-\hat{\mathrm{x}}_{i j k}\right)^{2}+\mathrm{Q} \sum^{\mathrm{n}} \mathrm{P}_{n}^{2} \ldots \ldots \ldots \ldots \ldots
\end{gathered}
$$

Here, $\mathrm{a}_{i k}^{I, I I}$ are the activities obtained from the experimental concentrations, I and II are the phases, $\mathbf{x}_{i j k}$ and $\hat{\mathbf{x}}_{i j k}$ are the experimental mole fraction values of the liquid phase and of the calculated tie line lying close to the considered experimental line, respectively, where i represents the components, $j$ the phases, and $\mathrm{k}$ the tie lines. $\mathrm{P}_{\mathrm{n}}$ and $\mathrm{Q}$ are the parameter and the constant values in the penalty term, respectively.
This penalty term was established to reduce the risk of multiple solutions associated with high parameter values. The values of the penalty terms were chosen taking into account Sorensen's recommendation [14]. Table 2 shows the structural parameters of the pure components taken from literature [15] and the optimised binary interaction parameters of the UNIQUAC and NRTL models, for the ternary system. The nonrandomness parameter for the NRTL equation is also given.

Goodness of fit, as measured by the r.m.s. deviation in mole fraction $\mathrm{F}$, is given by

$$
\mathrm{F}=100\left\{\sum_{k} \sum_{i} \sum_{j}\left(\mathrm{x}_{i j k}-\hat{\mathrm{x}}_{i j k}\right)^{2} / 2 n \mathrm{M}\right\}^{1 / 2}
$$

Where $\mathrm{n}$ is the number of components in the system. The r.m.s. relative error in the solute distribution ratio $\Delta \mathrm{m}$ is given by

$$
\Delta \mathrm{m}=100 \sum_{k}\left[\left\{\left(\mathrm{~m}_{k}-\hat{\mathrm{m}}_{k} / \mathrm{m}_{k}\right)^{2}\right\} / \mathrm{M}\right]^{1 / 2}
$$

Table 2: Residuals $F$ and $\Delta m$ for UNIQUAC and NRTL models, optimised parameters of the UNIQUAC and NRTL equations,

\begin{tabular}{|c|c|c|c|c|c|}
\hline F\% & $\% \Delta \mathbf{m}$ & $\mathbf{i}, \mathbf{j}$ & $a^{a j}{ }^{b} / K$ & $\mathbf{a j i}^{\mathbf{b}} / \mathbf{K}$ & $\mathbf{a}_{1 \varphi}$ \\
\hline \multicolumn{6}{|c|}{$\mathrm{T}=(278.15 \pm 0.05) \mathrm{K}$} \\
\hline \multicolumn{6}{|c|}{ UNIQUAC } \\
\hline \multirow[t]{3}{*}{0.3} & 9.8 & 1.2 & 216.42 & 98.078 & \\
\hline & & 1.3 & 21.889 & 636.69 & \\
\hline & & 2.3 & 224.34 & -31.41 & \\
\hline \multicolumn{6}{|c|}{ NRTL } \\
\hline \multirow[t]{3}{*}{0.2} & 11.5 & 1.2 & 552.6 & -1141.3 & 0.1 \\
\hline & & 1.3 & 394.45 & 424.43 & \\
\hline & & 2.3 & -856.88 & -658.88 & \\
\hline \multicolumn{6}{|c|}{$\mathrm{T}=(283.15 \pm 0.05) \mathrm{K}$} \\
\hline \multicolumn{6}{|c|}{ UNIQUAC } \\
\hline \multirow[t]{3}{*}{0.6} & 18.4 & 1.2 & 274.31 & 205.19 & \\
\hline & & 1.3 & 21.601 & 586.2 & \\
\hline & & 2.3 & 1301.4 & -123.13 & \\
\hline \multicolumn{6}{|l|}{ NRTL } \\
\hline \multirow[t]{3}{*}{0.6} & 18 & 1.2 & -68.795 & 2506.4 & 0.3 \\
\hline & & 1.3 & 515.76 & 430.57 & \\
\hline & & 2.3 & -569.32 & 372.79 & \\
\hline \multicolumn{6}{|c|}{$\mathrm{T}=(288.15 \pm 0.05) \mathrm{K}$} \\
\hline \multicolumn{6}{|c|}{ UNIQUAC } \\
\hline \multirow[t]{3}{*}{0.1} & 5.7 & 1.2 & -428.31 & 114.27 & \\
\hline & & 1.3 & 9.582 & 593.57 & \\
\hline & & 2.3 & -211.16 & -302.51 & \\
\hline \multicolumn{6}{|l|}{ NRTL } \\
\hline \multirow[t]{2}{*}{0.1} & 7.8 & 1.2 & 49.276 & -482.29 & 0.2 \\
\hline & & 1.3 & 450.8 & 367.88 & \\
\hline
\end{tabular}
and non-randomness parameter $\left(\mathrm{i}^{\text {th }}\right)$, of the ternary system ( $\mathrm{w} 1$ methanol $+w_{2}$ toluene $+w_{3}$ hexane at $T=(278.15,283.15,288.15$ and 293.15)Ka. 


\section{Recent Advances in Petrochemical Science}

\begin{tabular}{|l|c|c|c|c|c|}
\hline & & 2.3 & -772.96 & -109 & \\
\hline \multicolumn{7}{|c|}{ T= $(293.15 \pm 0.05) \mathrm{K}$} \\
\hline 0.1 & 2,6 & 1.2 & -352.42 & 133.69 & \\
\hline & & 1.3 & 5.2664 & 601.32 & \\
\hline & \multicolumn{7}{|c|}{ NRTL } \\
\hline \multicolumn{7}{|c|}{2.3} & -262.2 & -84.49 & \\
\hline 0.1 & 7.7 & 1.2 & -1047.9 & -1.3223 & 0.3 \\
\hline & & 1.3 & 484.92 & 435.17 & \\
\hline & & 2.3 & -548.73 & -738.08 & \\
\hline
\end{tabular}

\section{References}

1. Arce A, Blanco M, Soto A (1999) Determination and correlation of liquid-liquid equilibrium data for the quaternary system 1-octanol+2methoxy-2-methylbutane+water+methanol at $25{ }^{\circ} \mathrm{C}$. Fluid Phase Equilibria 158-160: 949-960.

2. García-Flores BE, Aguilar GG, Rincón ER, Trejo A (2001) Liquid-liquid phase diagrams of ternary systems as a function of temperature: isooctane+aromatic+methanol with and without wáter. Fluid Phase Equilibria 185(1-2): 275-293.

3. Gramajo MB, Bonatti CM, Sólimo HN (2003) Liquid-Liquid equilibria of ternary and quaternary systems with two hydrocarbons, an alcohol, and water at 303.15K-Systems Containing 2,2,4-Trimethylpentane, toluene, methanol, and water, or 2,2,4-trimethylpentane, toluene, ethanol, and water. Fluid Phase Equilibria 205(1): 53-67.

These residuals are listed in Table 2 for these two models. Here, $\mathrm{x}_{i j k}$ is the experimental mole fraction of the $\mathrm{i}^{\text {th }}$ component in the $\mathrm{j}^{\text {th }}$ phase on the kth tie line, $\hat{\mathrm{x}}_{i j k}$ is the corresponding calculated value, $\mathrm{m}_{k}$ and $\hat{\mathrm{m}}_{k}$ and are the experimental and calculated solute distribution ratios, respectively, given by $\mathrm{w}_{2}^{\prime \prime} / \mathrm{w}_{2}^{\prime}$. The goodness of fit in terms of the residuals $\mathrm{F}$ and $\Delta \mathrm{m}$ was satisfactory for the UNIQUAC and NRTL models, although this last residual shows relatively high values due to the large relative error associated with low concentrations of some compounds in both phases. Taking into account both residuals, the UNIQUAC equation fitted to the experimental data is more accurate than the NRTL model for this ternary system, as can be seen in Table 2 .

\section{Conclusion}

LLE of the ternary system methanol + toluene + hexane was investigated at 278.15, 283.15, 288.15 and $293.15 \mathrm{~K}$. From LLE results, we conclude that the mutual solubility of methanol in hexane is larger than that of hexane in methanol at four temperatures. This ternary system also shows that the solubility increases when temperature increases as can be seen in Figure 1. Consequently, this blend could be used as a summer reformulated gasoline since it would not show separation of phases.

As can be seen, the solubility of this ternary system is sensitive to changes in a short range of temperature. The UNIQUAC and NRTL models show low values of both residuals, particularly for the residual $\mathrm{F}$, although for $\Delta \mathrm{m}$ is high at $283.15 \mathrm{~K}$ (Table 1 ) due to low concentrations of some compounds in both phases. Furthermore, taking into account both residuals, the UNIQUAC equation is more accurate than the NRTL one, except at $283.15 \mathrm{~K}$.

\section{Acknowledgement}

Financial support from the Consejo de Investigaciones de la Universidad Nacional de Tucumán, Argentina (CIUNT, Grant 26/E518) and Secretaria de Políticas Universitarias de la Nación Argentina "Proyecto Jorge Sabato" Res. № 1150 SPU, 20/02/2016 are gratefully acknowledged.

4. Chen J, Li-Pin D, Guo MJ, Yang FW, Cheng LZ, et al. (2000) Liquid-liquid equilibria of multi-component systems including n-hexane, n-octane, benzene, toluene, xylene and sulfolane at $298.15 \mathrm{~K}$ and atmospheric pressure. Fluid Phase Equilib 173(1): 109-119.

5. Gramajo MB, Bonatti CM, Sólimo HN (2003) (Liquid + liquid) equilibria of ternary and quaternary systems with two hydrocarbons, an alcohol, and water at $303.15 \mathrm{~K}$. Systems containing cyclohexane, benzene, ethanol, and water. The Journal of Chemical Thermodynamics 35(12): 2055-2065.

6. Gramajo MB, Bonatti CM, Sólimo HN (2005) Liquid-liquid equilibria for the quaternary system water plus methyl tert-butyl ether plus benzene plus cyclohexane and its constituent partially miscible ternary systems at 303.15K. Energy and Fuels 19(5): 1977-1983.

7. Flores BEG, Doz MBG, Trejo A (2005) Liquid-liquid equilibria for pseudoternary systems: isooctane-benzene-(methanol + water). Fluid Phase Equilibria 230(1-2): 121-130.

8. Renon H, Prausnitz JM (1968) Local compositions in thermodynamic excess functions for liquid mixtures. AIChE Journal 14(1): 135-144.

9. Abrams DS, Prausnitz JM (1975) Statistical thermodynamics of liquid mixtures: A new expression for the excess Gibbs energy of partly or completely miscible systems. AIChE Journal 21(1): 116-128.

10. Gramajo MB, Cases AM (2009) (Liquid+Liquid) equilibria of methanol+isooctane+methylcyclohexane+ethylbenzene quaternary system at $\mathrm{T}=303.15 \mathrm{~K}$. Fluid Phase Equilibria 304(1-2): 68-73.

11. Gramajo MB, Cases AM, Bonatti CM, Sólimo HN (2009) Influence of temperature on the (liquid + liquid) equilibria of $\{3$-methyl pentane + cyclopentane + methanol $\}$ ternary system at $\mathrm{T}=(293.15,297.15$, and 299.15)K. Journal Of Chemical Thermodynamics 41(11): 1279-1283.

12. Treybal RE (1963) Liquid Extraction ( $\left.2^{\text {nd }} e d n\right)$, McGraw Hill, New York, USA.

13. Gomis V, Ruíz F, Asensi JC, Saquete MD (1997) Procedure for checking and fitting experimental liquid-liquid equilibrium data. Fluid Phase Equilibria 129(1-2): 15.

14. Sørensen JM (1980) ESTM Phase Equilibria and Separation Processes MAN 8106 ESTM: Estimation of UNIQUAC and NRTL Parameters from Ternary LLE Data, Instituttet for Kemiteknik, Lyngby, Denmark.

15. Sørensen JM, Arlt W (1980) Liquid-Liquid Equilibrium Data Collection. Ternary and Quaternary systems. Dechema Chemistry Data Series, Germany, 5(3). 
This work is licensed under Creative Commons Attribution 4.0 Licens DOI: 10.19080/RAPSCI.2017.03.555602

\section{Your next submission with Juniper Publishers} will reach you the below assets

- Quality Editorial service

- Swift Peer Review

- Reprints availability

- E-prints Service

- Manuscript Podcast for convenient understanding

- Global attainment for your research

- Manuscript accessibility in different formats

( Pdf, E-pub, Full Text, Audio)

- Unceasing customer service

Track the below URL for one-step submission https://juniperpublishers.com/online-submission.php 